\title{
Engineered M13 Nanofiber Accelerates Ischemic Neovascularization by Enhancing Endothelial Progenitor Cells
}

\author{
Jun Hee Lee ${ }^{1}$ Sung Wook $\mathrm{Kim}^{2} \cdot$ Seung Taek $\mathrm{Ji}^{2} \cdot$ Yeon Ju Kim${ }^{2} \cdot$ \\ Woong Bi Jang ${ }^{2} \cdot \mathrm{Jin}^{-W o o} \mathrm{Oh}^{3} \cdot \mathrm{Jaho} \mathrm{Kim}^{4} \cdot$ So Young $\mathrm{Yoo}^{6} \cdot$ Sang Hong Beak ${ }^{7}$. \\ Sang-Mo Kwon ${ }^{2,4,5}$
}

Received: 23 May 2017/Revised: 8 July 2017/Accepted: 16 July 2017/Published online: 28 August 2017

(C) The Korean Tissue Engineering and Regenerative Medicine Society and Springer Science+Business Media B.V. 2017

\begin{abstract}
Dysfunction or loss of blood vessel causes several ischemic diseases. Although endothelial progenitor cells (EPCs) are a promising source for cell-based therapy, ischemia-induced pathophysiological condition limits the recovery rate by causing drastic cell death. To overcome this issue, we attempted to develop a cell-targeted peptide delivery and priming system to enhance EPCbased neovascularization using an engineered M13 bacteriophage harboring nanofibrous tubes displaying 2700 multiple functional motifs. The M13 nanofiber was modified by displaying RGD, which is an integrin-docking peptide, on the minor coat protein, and by mutilayering SDKP motifs, which are the key active sites for thymosin $\beta 4$, on the major coat protein. The engineered M13 nanofiber dramatically enhanced ischemic neovascularization by activating intracellular and extracellular processes such as proliferation, migration, and tube formation in the EPCs. Furthermore, transplantation of the primed EPCs with the M13 nanofiber harboring RGD and SDKP facilitated functional recovery and neovascularization in a murine hindlimb ischemia model. Overall, this study demonstrates the effectiveness of the M13 nanofiber-based novel peptide delivery and priming strategy in promoting EPC bioactivity and neovessel regeneration. To our knowledge, this is first report on M13 nanofibers harboring dual functional motifs, the use of which might be a novel strategy for stem and progenitor cell therapy against cardiovascular ischemic diseases.
\end{abstract}

Keywords M13 bacteriophage $\cdot$ Endothelial progenitor cell $\cdot$ RGD $\cdot$ SDKP $\cdot$ Neovascularization

Electronic supplementary material The online version of this article (doi:10.1007/s13770-017-0074-x) contains supplementary material, which is available to authorized users.

Jun Hee Lee and Sung Wook Kim have contributed equally to this work.

Sang Hong Beak

whitesh@ catholic.ac.kr

$\triangle$ Sang-Mo Kwon

smkwon323@hotmail.com

1 Department of Pharmacology and Toxicology, University of Alabama at Birmingham School of Medicine, Birmingham, AL 35294, USA

2 Laboratory for Vascular Medicine and Stem Cell Biology, Department of Physiology, School of Medicine, Medical Research Institute, Pusan National University, 49,

Busandaehak-ro, Mulgeum-eup, Yangsan 50612, Republic of Korea

3 Department of Nanoenergy Engineering, Pusan National University, 2, Busandaehak-ro 63beon-gil, Geumjeong-gu, Busan 46241, Republic of Korea
4 Research Institute of Convergence Biomedical Science and Technology, Pusan National University School of Medicine, 49, Busandaehak-ro, Mulgeum-eup, Yangsan 50612, Republic of Korea

5 Immunoregulatory Therapeutics Group in Brain Busan 21 Project, Pusan National University, 49, Busandaehak-ro, Mulgeum-eup, Yangsan 50612, Republic of Korea

6 BIO-IT Foundry Technology Institute, Pusan National University, 2, Busandaehak-ro 63beon-gil, Geumjeong-gu, Busan 46241, Republic of Korea

7 Laboratory of Cardiovascular Disease, Division of Cardiology, School of Medicine, The Catholic University of Korea, 222, Banpo-daero, Seocho-gu, Seoul 06591, Republic of Korea 


\section{Introduction}

Since the discovery of vasculogenic stem/progenitor cells called as endothelial progenitor cells (EPCs) in human blood, many researches have proposed patient peripheral blood-derived or cord blood-derived EPCs to be a promising cell source for therapeutic neovascularization against several ischemic diseases including cardiovascular diseases, peripheral arterial diseases, and neuronal ischemic diseases [1-3]. The challenge of such EPC-based therapy is the dysfunction or loss of the vascular system, which limits the recovery rate; this challenge needs to be overcome by strategic modulation of pathophysiological badsoil conditions in ischemic tissues, which represent harsh oxidative stress and aggressive inflammatory reactions, as well as oxygen and nutrient insufficiency in the ischemic injured tissues, which eventually result in low engraftment and limited therapeutic efficacy [4]. Moreover, ex vivo cell expansion to increase the amount of EPCs isolated from patients induces cellular replicative senescence and changes at the genomic and/ or epigenomic level and reduces activating signaling at the proteomic level; such phenomena are also accompanied by loss of cellular functionalities including self-renewal, migration, and homing [4-6]. To improve stem/progenitor cell engraftment and survival in ischemic tissues, several researchers have suggested various strategies including cell priming, cytokine preconditioning, genetic modification, cell microencapsulation, magnetic targeting, and multiple tissue engineering strategies for manipulation $[4,7]$. In more recent studies, combined strategies for biological regeneration have shown to be more effective synergisms than the currently used one-stop and single-cell strategies, thus indicating that the development of efficient protocols to protect ischemic microenvironment-mediated transplanted stem cell death is extremely important for the successful application of stem/progenitor cell-based therapy [7].

The delivery of specific therapeutic molecules is a key technology for the development of combined strategies for primed stem/progenitor cell-based therapy. The recently adopted conventional cell-priming strategies with multiple growth factors, cytokine cocktails, and functional peptides represent limited and low efficacy in terms of blood vessel recovery because of unstable interactions between the cell and the target molecules, non-specific reactions, improper distribution, and cell toxicity. The M13 bacteriophage (referred to as the M13 nanofiber), which is a bacterium-hosted bio-safe virus harboring nanofiber-like tubes, can easily express various functional proteins and peptides on its surface [8-11]. The M13 phage is composed of 2700 copies of major coat proteins (pVIII) and 5 copies of minor coat proteins (pIII) [12] and displays the integrin-binding peptide (Arg-Gly-Asp; RGD), which binds to integrin-expressing cells and internalizes into the cells $[13,14]$. In particular, the use of RGD peptide-displaying M13 phage/poly (lactic-co-glycolic acid) nanofibers as cell-adhesive matrices promotes smooth muscle cell adhesion, myoblast differentiation, proliferation of fibroblasts, and myogenesis of myoblasts [15-18]. In addition, RGD peptide-displaying M13 phage-based films induce the osteogenic differentiation of mesenchymal stem cells without any osteogenic supplements [11]. These findings suggest that functional peptide-displaying M13 nanofibers are a promising candidate for use in combined strategies for biological repair.

Although the engineered M13 nanofiber is a biocompatible and attractive biomaterial for targeting specific molecules in various cells, many studies have mainly focused on the development of M13 phages displaying only one functional peptide on the pVIII sites. Moreover, because of the filamentous structure of the M13 phage, several researchers have developed engineered M13 phagebased nano-/macro-fibers and films to modulate cell behaviors. To shift this paradigm, in this study, we aimed to develop a M13 phage-based double functional peptidecarrying system, where RGD peptides were displayed in the pIII minor coat proteins to bind to integrin-expressing cells in order to construct an artificial niche.

Ischemia triggers the generation of reactive oxygen species (ROS), and ROS in ischemic sites inhibit the adhesion of transplanted stem/progenitor cells to the extracellular matrix (ECM), resulting in cell apoptosis; this process is known as anoikis [19]. Since the RGD peptide derived from fibronectin is a major adhesive motif in ECM, and because stem cells come into contact with ECM in the niche, the RGD peptide-displaying M13 phage establishes an artificial ECM as the stem cell niche and prevents anoikis [20-22]. In the $\mathrm{pVIII}$ major coat proteins, a small biomolecule peptide of thymosin $\beta 4$ (Ser-AspLys-Pro; SDKP) was displayed to improve cell functions including proliferation, tube formation, anti-oxidant effect, and immunomodulation. Thymosin $\beta 4$ has various biological activities such as anti-microbial, anti-apoptotic, and anti-inflammatory activity [23]. Ac-SDKP, which is the active site of thymosin $\beta 4$, enhances cell survival, inhibits apoptosis, and induces angiogenesis $[23,24]$. In the current study, we developed an engineered M13 nanofiber harboring both RGD and SDKP motifs and investigated the priming effect and in vivo and in vitro vasculogenic effect of the EPCs primed with the therapeutic M13 nanofiber against cardiovascular diseases.

\section{Materials and methods}

\subsection{Ethical statement}

For isolation of EPCs, human umbilical cord blood (hUCB) was collected from healthy volunteers after obtaining informed consent according to the protocol approved by the Ethics Review Board of the Pusan National University 
Yansan Hospital, Republic of Korea. The consent was written and approved. The Institutional Review Board of the Pusan National University Yangsan Hospital, Republic of Korea (Approval No. PNUH-2012-19) approved all surgical interventions and postoperative animal care. For animal experiments, male 8 -week-old $\mathrm{Balb} / \mathrm{C}$ nude mice (Biogenomics, Seoul, Korea) were maintained under a 12-h light/dark cycle and the experiments were conducted in accordance with the regulations of Pusan National University. All the procedures were performed in accordance with the policies of the Institutional Animal Care and Use Committee of Pusan National University of Korea (IACUC090017).

\subsection{Isolation, culture, and characterization of EPCs}

Human EPCs were isolated from human umbilical cord blood (hUCB) as reported previously [25]. Briefly, hUCB was collected from healthy volunteers after obtaining informed consent according to the protocol approved by the Institutional Review Board of the Pusan National University Yangsan Hospital, Republic of Korea (Approval No. PNUH-2012-19). Total mononuclear cells were isolated by Ficoll (GE healthcare, Buckinghamshire, UK) gradient density centrifugation of the hUCB. Freshly isolated cells were then cultured in endothelial growth medium-2 (EGM-2) supplemented with 5\% fetal bovine serum, human vascular endothelial growth factor, human basic fibroblast growth factor, human epidermal growth factor, human insulin-like growth factor 1, ascorbic acid, and GA1000 (Lonza, Walkersville, MD, USA). After 4 days in culture, non-adherent cells were discarded, and the attached cells were cultured further. The cells were subjected to long-term culture to allow for the formation of spindle-shaped colonies, and the medium was replenished every 14-21 days. For the characterization of several surface and pivotal functional markers, flow cytometry analysis was performed. The EPCs were positive for endothelial lineage markers (CD31 and VEGFR2) and hematopoietic stem cell markers (CD34, CXCR4, and c-Kit) and negative for hematopoietic markers, such as CD11b, CD14, and CD45 (Figure S1, Supporting Information).

\subsection{Genetic engineering of the M13 nanofiber}

To engineer the M13 bacteriophage displaying both RGD and SDKP, we genetically engineered the major coat protein pVIII and minor coat protein pIII of the M13 bacteriophage using a recombinant DNA engineering technique as reported previously [26-28]. To construct the RGD peptide on the minor coat protein and the SDKP peptide on the major coat protein, M13KE single-stranded phage
(New England Biolabs, Ipswich, MA, USA) was used as a base for the library and insert construction. We used a partially constrained library method to design a stable peptide sequence. This was accomplished by site directed mutagenesis using methods described in the QuikChange Kit (Stratagene, La Jolla, CA, USA). Following mutagenesis, the resulting phages were verified by DNA sequencing (Cosmo Genetech, Seoul, Korea), and the viability of the phages was assessed by plaque forming units (PFU). Several types of engineered M13 bacteriophages were treated on EPCs for $24 \mathrm{~h}$.

\subsection{Immunocytochemistry}

EPCs grown on a microscope cover glass were washed in PBS, fixed in $4 \%$ paraformaldehyde (USB Corporation, Santa Clara, CA, USA) for $10 \mathrm{~min}$, permeabilized with $0.2 \%(\mathrm{w} / \mathrm{v})$ Triton $\mathrm{X}-100$ in PBS for $5 \mathrm{~min}$, and then incubated in PBS containing $5 \%$ bovine serum albumin (BSA; Sigma-Aldrich, St. Louis, MO, USA) for $2 \mathrm{~h}$ to block non-specific binding sites. The cells were then incubated with primary anti-M13 antibody (Abcam, Cambridge, UK), and secondary antibody Alexa-488 (Thermo Fisher Scientific, Waltham, MA, USA). The nuclei were stained with 4',6-diaminido-2-phenylindol (SigmaAldrich), and the immunostained cells were imaged under a confocal microscope (Olympus, Tokyo, Japan).

\subsection{Cell viability assay}

The viability of the EPCs following treatment with the engineered M13 nanofiber was assessed using a WST-1 assay kit based on the measurement of water-soluble tetrazolium salt (LPS Solution, Saejeon, Korea); the assay was carried out according to the manufacturer's instructions. Briefly, after treatment with the M13 phage at various concentrations $\left(0-10^{5} \mathrm{PFU} / \mathrm{cell}\right)$, the EPCs were incubated with tetrazolium salt for $4 \mathrm{~h}$ at $37{ }^{\circ} \mathrm{C}$ in $5 \% \mathrm{CO}^{2}$. The formazan dye formed was then quantified by measuring the absorbance at $450 \mathrm{~nm}$ using a microplate reader (Tecan, Mannedorf, Switzerland).

\subsection{Cell cycle analysis}

The EPCs treated with the engineered M13 nanofiber were fixed with $70 \%$ ethanol at $-20{ }^{\circ} \mathrm{C}$ for $1 \mathrm{~h}$. After washing with cold PBS, the cells were incubated with RNase A (Sigma-Aldrich) and the DNA-intercalating dye, propidium iodide (PI; Sigma). Cell cycle histograms of the PIstained EPCs were constructed by fluorescence-activated cell sorting (FACS; BD FACSCanto II, San Jose, CA, USA). 


\subsection{Western blot analysis}

Total protein was extracted using RIPA lysis buffer (Thermo Fisher Scientific). The cell lysates were separated by sodium dodecyl sulfate-polyacrylamide gel electrophoresis, and the proteins were transferred to polyvinylidene fluoride membranes (Millipore, Billerica, MA, USA). The membranes were then blocked with $5 \%$ BSA and incubated with primary antibodies against cyclin D, PRX I, PRX II, JNK, phosphor-JNK (p-JNK), p38, p-p38, MCP-1, and $\beta$-actin (Santa Cruz Biotechnology, Santa Cruz, CA, USA). After incubation of the membranes with peroxidase-conjugated secondary antibodies (Santa Cruz Biotechnology), bands were visualized using enhanced chemiluminescence reagents (Amersham Biosciences, Uppsala, Sweden).

\subsection{Trans-well migration assay}

The trans-well migration assay was performed using a modified Boyden chamber (Thermo Fischer Scientific) containing a polycarbonate membrane filter $(8 \mu \mathrm{m}$ pore size). The upper chamber contained EPCs in EGM-2 supplemented with 1\% FBS (Lonza), and the lower chamber contained EGM-2 supplemented with 5\% fetal bovine serum, human vascular endothelial growth factor, human basic fibroblast growth factor, human epidermal growth factor, human insulin-like growth factor 1, ascorbic acid, and GA-1000 (Lonza). The cells were incubated for $12 \mathrm{~h}$ at $37{ }^{\circ} \mathrm{C}$ in a $5 \%-\mathrm{CO}_{2}$ incubator. Non-migrated cells were scraped off the upper surface of the membrane with a cotton swab, and the migrated cells remaining on the bottom surface were imaged under a confocal microscope (Olympus) after staining with DAPI (Sigma-Aldrich).

\subsection{Scratched wound healing assay}

To investigate the migratory capacity of the EPCs, the cells were plated in 6-well plates and grown until confluence. The monolayer was wounded with a cell scraper, and the detached cells were removed by washing with media. After $6 \mathrm{~h}$ of incubation, the migrated cells were observed under a light microscope (Olympus) with a $40 \times$ objective lens.

\subsection{Tube formation assay}

Matrigel tube formation assay was performed to confirm the endothelial differentiation potential of EPCs. Matrigel (BD Biosciences, San Jose, CA, USA) was added to 96-well plates and incubated at $37{ }^{\circ} \mathrm{C}$ for $1 \mathrm{~h}$. The EPCs were then seeded onto the Matrigel-coated plates and cultured at $37{ }^{\circ} \mathrm{C}$ for $6 \mathrm{~h}$ in a $5 \% \mathrm{CO}_{2}$ incubator. Once tube formation was observed, images were captured using a light microscope (Olympus) with a $40 \times$ objective lens.

\subsection{Murine hindlimb ischemia model}

Male 8-week-old Balb/C nude mice (Biogenomics, Seoul, Korea) were maintained under a 12-h light/dark cycle and the experiments were conducted in accordance with the regulations of Pusan National University. All the procedures were performed in accordance with the policies of the Institutional Animal Care and Use Committee of Pusan National University of Korea (IACUC090017). For developing the murine hindlimb ischemia model, ischemia was induced by ligation and amputation of the proximal femoral artery of the mice. No later than $6 \mathrm{~h}$ after the operation, PBS, non-treated EPCs, EPCs treated with the wild-type M13 phage, EPCs treated with M13 phage displaying only RGD peptide on the minor coat protein, and EPCs treated with M13 phage displaying RGD peptide on the minor coat protein and SDKP peptide on the major coat protein were transplanted intramuscularly into the ischemic sites $\left(5 \times 10^{5}\right.$ cells/60 $\mu$ l PBS per mouse). Blood perfusion was investigated by measuring the ratio of the ischemic (left) limb blood flow/non-ischemic (right) limb blood flow on postoperative days $0,3,7,14,21$, and 28 using laser Doppler perfusion imaging (LDPI; Moor Instruments, Wilmington, DE, USA).

\subsection{Immunohistochemistry}

After 3 or 28 days following surgery, the ischemic sites were removed and fixed with $4 \%$ paraformaldehyde. Each sample was embedded in paraffin, and immunofluorescent staining was performed using primary antibodies against PRX I (Santa Cruz Biotechnology), PRX II (Santa Cruz Biotechnology), MCP-1 (Santa Cruz Biotechnology), $\alpha$ SMA (Abcam), CD31 (Abcam), human nuclear antigen (HNA; Millipore), cleaved caspase-3 (Santa Cruz Biotechnology), PCNA (Santa Cruz Biotechnology), and human-specific CD31 (Abcam), and secondary antibodies Alexa-488 and Alexa-594 (Thermo Fisher Scientific). Nuclei were stained with DAPI (Sigma-Aldrich), and the immunostained tissue slides were imaged under a confocal microscope (Olympus).

\subsection{Statistical analysis}

All the data were expressed as mean \pm standard error of the mean (SEM). Statistical significance was assessed using Student's $t$ test, where differences with $p<0.05$ were considered significant. 
A Plasmid mapping

\begin{tabular}{|c|c|c|c|c|c|}
\hline \multirow{2}{*}{ P8-S } & M13 & VIII & \multicolumn{3}{|c|}{ III } \\
\hline & $M 13^{R}$ & VIII & III & RGD & III \\
\hline & $M 13^{R+S}$ & VIII SDKP VIII & III & RGD & III \\
\hline
\end{tabular}
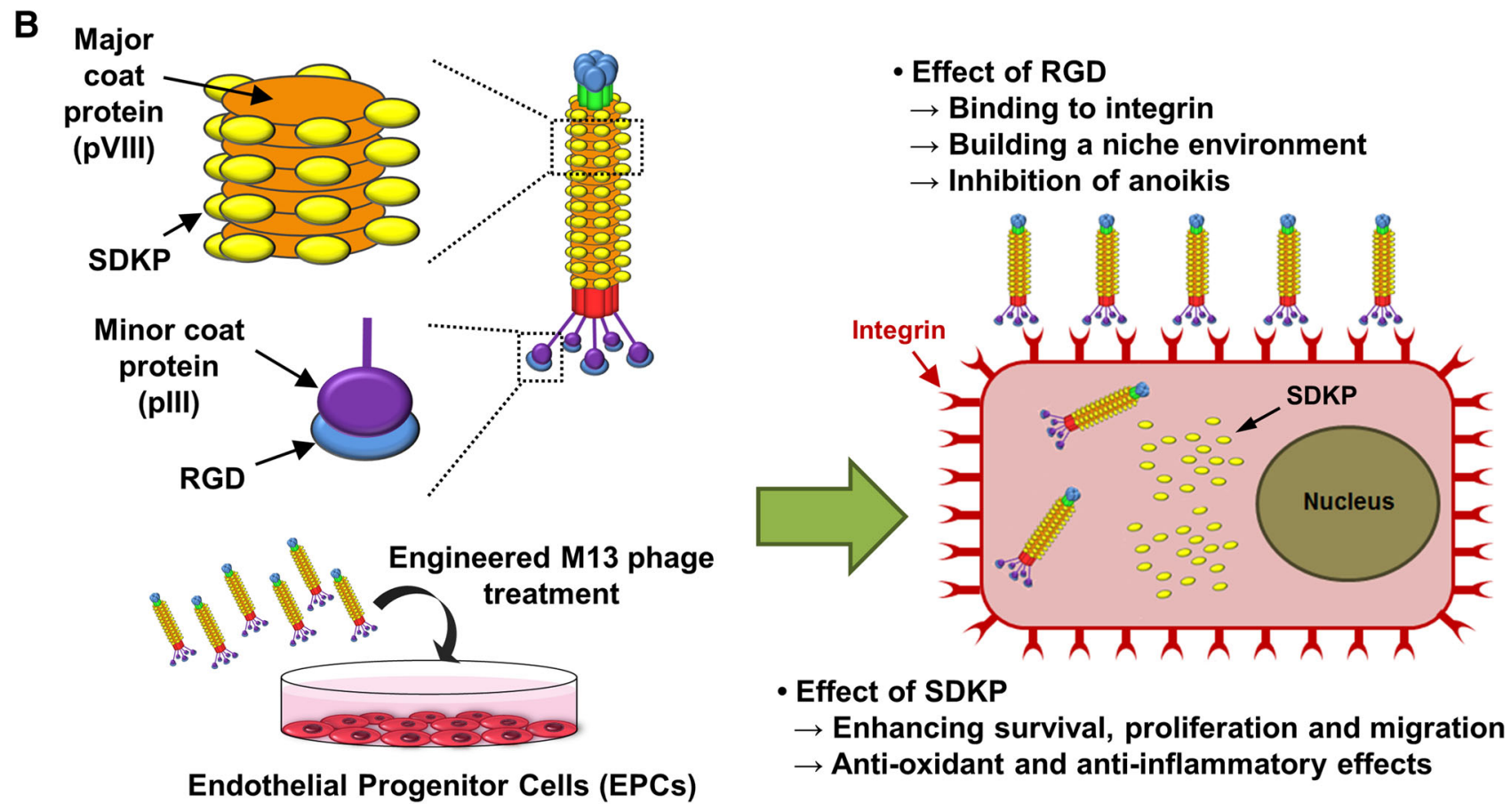

\section{- Effect of SDKP \\ $\rightarrow$ Enhancing survival, proliferation and migration \\ $\rightarrow$ Anti-oxidant and anti-inflammatory effects}

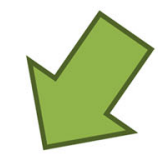

\section{Transplantation of EPC treated engineered M13 phage}
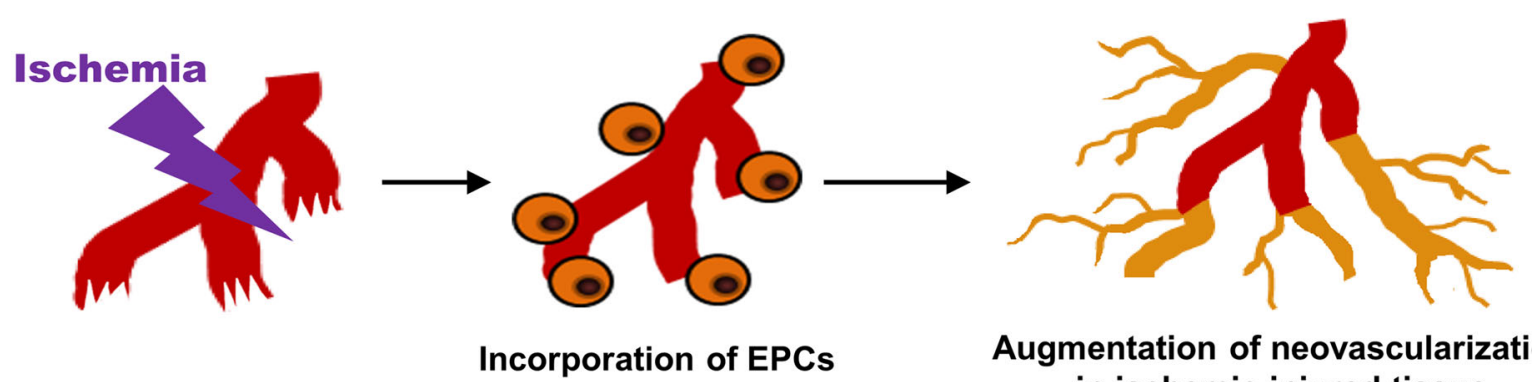

\section{Augmentation of neovascularization in ischemic injured tissue}

Fig. 1 Schematic illustration of experimental design for the engineered M13 nanophage. A Strategy for the construction of the M13 bacteriophage (M13 phage) for intracellular delivery of SDKP peptide into endothelial progenitor cells (EPCs). M13 phage was genetically modified to display an integrin-binding peptide, RGD, on the minor coat protein (pIII, P3) and a functional peptide, SDKP, which is an effective peptide site of thymosin $\beta 4$, on the major coat protein (pVIII, P8). B Schematic representation of the targeted delivery of the engineered M13 phage into EPCs and the beneficial effect of the engineered M13 phage on functionalities of the EPCs. (Color figure online) 
A

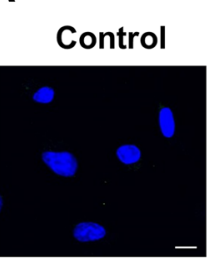

PFU / 1 cell
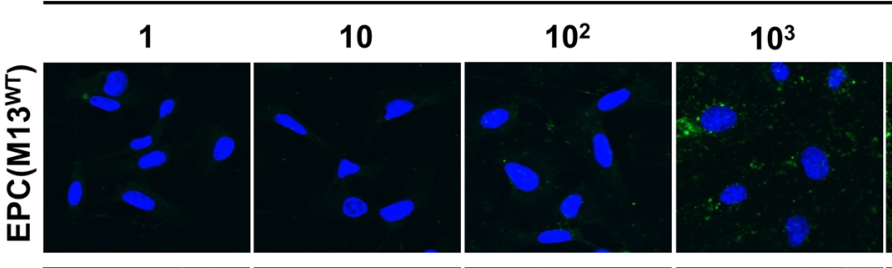

$10^{4}$

$10^{5}$
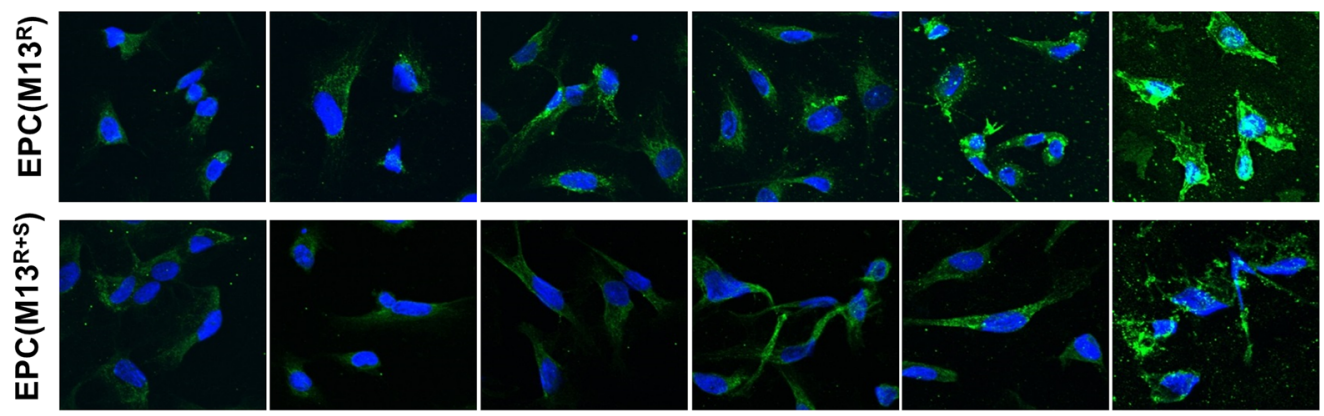

B

$\operatorname{EPC}\left(M 13^{W T}\right)$
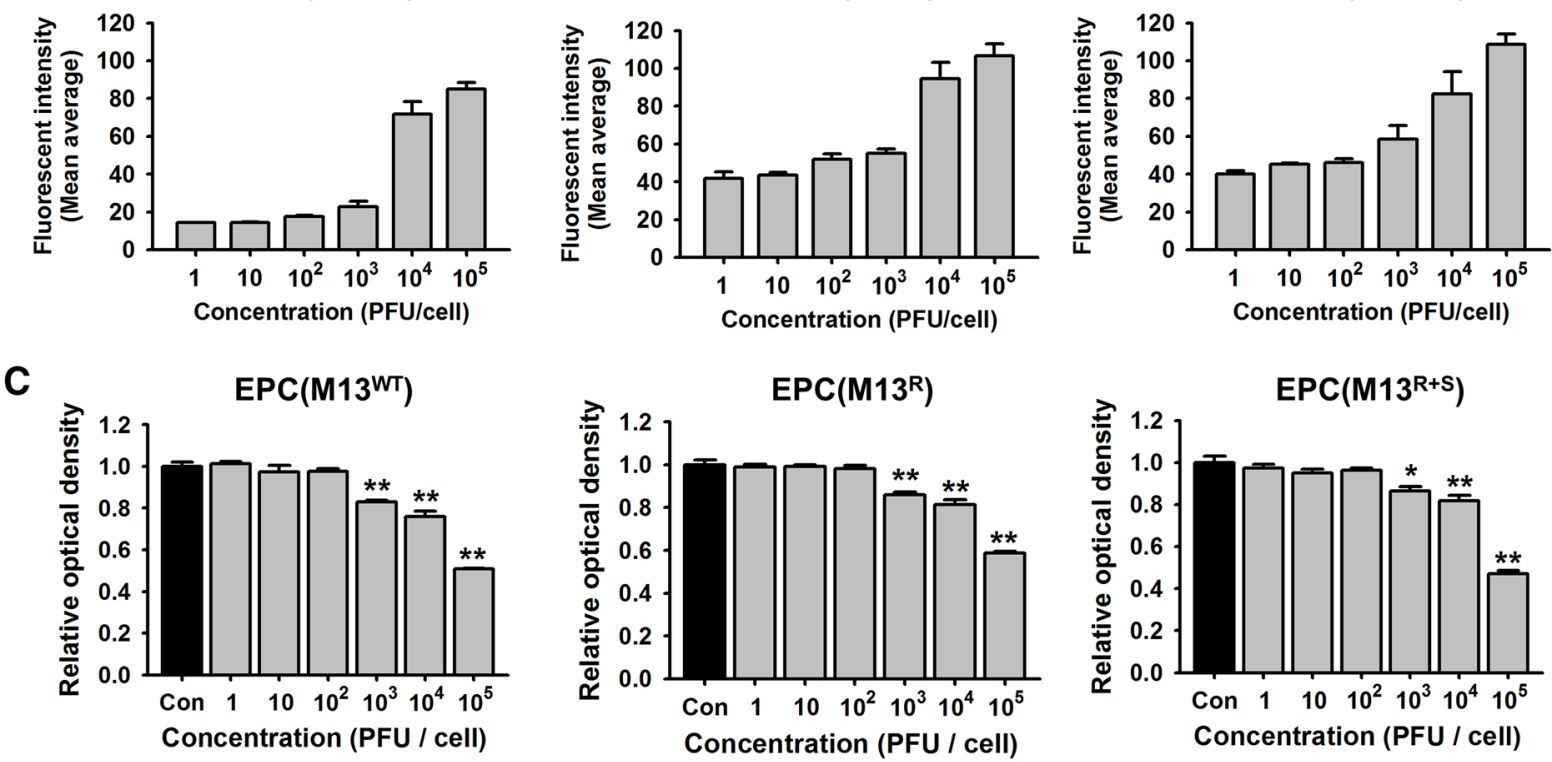

D

$E P C\left(M 13^{R+S}\right)$

$\mathbf{E}$
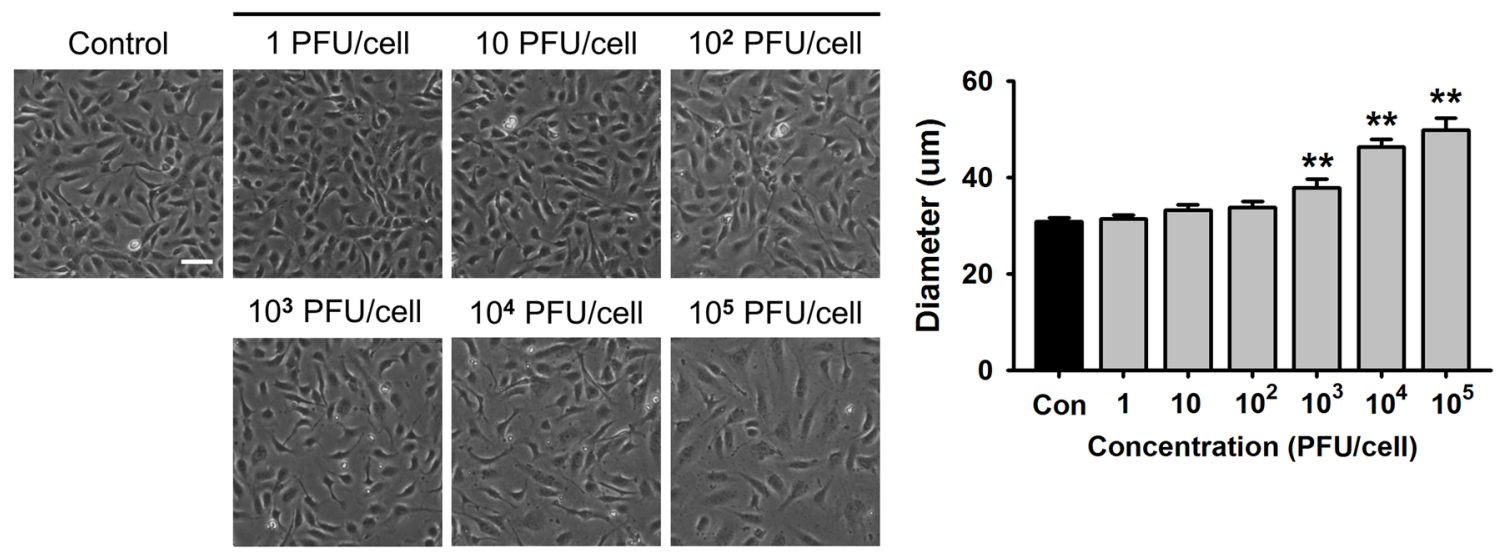
4Fig. 2 Effect of the engineered M13 nanophage on the EPCs. A Adhesion of the wild-type M13 phage (M13 ${ }^{\mathrm{WT}}$ ) and the engineered M13 phages displaying RGD $\left(\mathrm{M} 13^{\mathrm{R}}\right)$ or RGD and SDKP $\left(\mathrm{M} 13^{\mathrm{R}+\mathrm{S}}\right)$ on the EPCs. The M13 phages were immunostained with anti-M13 bacteriophage antibody (green). The nuclei were stained with DAPI (Blue). Scale bar $=10 \mu \mathrm{m}$. B Quantification of adhesion of the engineered M13 phage at various concentrations $\left(0-10^{5}\right.$ plaque forming unit (PFU)/cell) on the EPCs. C After treatment with the engineered M13 phage (0-10 5 PFU/cell), the viability of the EPCs was assessed. Values are expressed as the mean \pm standard error of the mean (SEM). $* * p<0.01$ versus control. D The morphologies of the EPCs after treatment with the M13 phage displaying RGD and $\operatorname{SDKP}\left(0-10^{5} \mathrm{PFU} / \mathrm{cell}\right)$ for $24 \mathrm{~h}$. Scale bar $=50 \mu \mathrm{m}$. E Quantification of the diameter of the EPCs after treatment with the M13 phage displaying RGD and SDKP. Values are expressed as the mean \pm SEM. $* * p<0.01$ versus control. (Color figure online)

\section{Results}

\subsection{Production of the engineered M13 nanofiber displaying RGD and SDKP peptides}

To construct a novel engineered M13 nanofiber with functional peptide delivery function, we genetically modified the M13 phage to display RGD, which is an integrinbinding peptide, on the pIII minor coat protein and SDKP, which is the active site of thymosin $\beta 4$, on the pVIII major coat protein (M13 ${ }^{\mathrm{R}+\mathrm{S}}$; Fig. 1A). Wild type M13 (M13 ${ }^{\mathrm{WT}}$ ) and the M13 phage displaying RGD on pIII without SDKP $\left(\mathrm{M} 13^{\mathrm{R}}\right)$ was used as a control (Fig. 1A). We hypothesized that EPCs treated with $\mathrm{M} 13^{\mathrm{R}+\mathrm{S}}$ may show enhanced bioactivities such as proliferation, migration, tube formation, anti-oxidant effect, and anti-inflammatory effect, and that the transplantation of the primed EPCs into the ischemic tissues might result in blood vessel recovery through blood perfusion, limb salvages, and neovascularization, in a hindlimb ischemia model (Fig. 1B).

To verify this hypothesis, we first determined the optimal concentration of the M13 nanofiber for the priming of the EPCs. The adhesion of the M13 nanofiber on the EPCs was confirmed by immunofluorescent staining for anti-M13 phage (Fig. 2A). While M13 ${ }^{\text {WT }}$ rarely adhered to the EPCs at a concentration of $10^{2}$ plaque forming unit $(\mathrm{PFU}) / \mathrm{cell}$, the adhesion of $\mathrm{M} 13^{\mathrm{R}}$ and $\mathrm{M} 13^{\mathrm{R}+\mathrm{S}}$ on the EPCs was significantly higher than that of $\mathrm{M} 13^{\mathrm{WT}}$ at $10^{2} \mathrm{PFU} / \mathrm{cell}$ (Fig. 2B). These results suggest that the expression of RGD on the M13 phage increases the adhesion of the phage on EPCs.

To explore the cytotoxic effect of the M13 phage on the EPCs, cell survival analysis was performed. The survival of the EPCs treated with $\mathrm{M} 13^{\mathrm{WT}}, \mathrm{M} 13^{\mathrm{R}}$, or $\mathrm{M} 13^{\mathrm{R}+\mathrm{S}}$ was significantly decreased at a concentration of $10^{3} \mathrm{PFU} /$ cell compared with that of the control (Fig. 2C). In addition, the morphologies of the EPCs treated with $\mathrm{M} 13^{\mathrm{R}+\mathrm{S}}$ were significantly changed at a concentration of $10^{3} \mathrm{PFU} /$ cell
(Fig. 2D, E). These findings indicate that the optimal concentration of the engineered M13 nanofiber in the EPCs is $10^{2} \mathrm{PFU} / \mathrm{cell}$.

To confirm the internalization of the RGD-displaying M13 phage into the EPCs, after treatment of the EPCs with the M13 ${ }^{\mathrm{R}+\mathrm{S}}$ phage for $6 \mathrm{~h}$, immunofluorescent staining was performed for detecting the internalized $\mathrm{M} 13^{\mathrm{R}+\mathrm{S}}$ phage in the EPCs, and the stained slides were scanned along the Z-axis by confocal microscopy (Figure S2, Supporting Information). The scanned images indicated that the $\mathrm{M} 13^{\mathrm{R}+\mathrm{S}}$ phage was internalized into the EPCs. These data suggested that a M13 phage displaying both RGD and SDKP would significantly increase the adhesion and internalization in the EPCs compared with that observed for the wild M13 phage and that the optimal concentration of the M13 pages was $10^{2} \mathrm{PFU} / \mathrm{cell}$.

\subsection{M13 nanofiber displaying both RGD and SDKP enhances the bioactivities of the EPCs}

To confirm the effect of the engineered M13 phage on the proliferative potential of the EPCs, cell cycle analysis was performed using flow cytometry for PI staining (Fig. 3A). Treatment with the RGD-expressing M13 phage resulted in a greater number of cells in the S phase than that observed for the non-treated EPCs (Fig. 3B). In addition, the percentage of cells in the $S$ phase was significantly higher in the EPCs treated with $\mathrm{M} 13^{\mathrm{R}+\mathrm{S}}$ than in those treated with $\mathrm{M} 13^{\mathrm{R}}$ (Fig. 3B). To investigate the expression of cell cycle-associated proteins, the level of cyclin D was assessed using western blot, and it was found that cyclin D expression was significantly augmented by treatment with $\mathrm{M} 13^{\mathrm{R}}$ and $\mathrm{M} 13^{\mathrm{R}+\mathrm{S}}$ (Fig. 3C). Our findings reveal that our engineered M13 phage carrying both RGD and SDKP increased EPC proliferation by regulating the expression of cyclin D.

To investigate the migration capacity of the EPCs after treatment with the engineered M13 nanofiber, the migration capacity of the EPCs was assessed using the trans-well assay (Fig. 3D). The EPCs treated with $\mathrm{M} 13^{\mathrm{R}+\mathrm{S}}$ showed significantly enhanced migration capacity compared to those of the other groups (Fig. 3E). In addition, a scratched wound healing assay revealed that treatment with $\mathrm{M} 13^{\mathrm{R}+\mathrm{S}}$ significantly increased EPC migration (Fig. 3F).

To determine whether the engineered M13 nanofiber improved tube formation in the EPCs, a Matrigel tube formation assay was performed (Fig. 3G). Tube formation capacity was significantly increased after treatment with $\mathrm{M} 13^{\mathrm{R}+\mathrm{S}}$ compared to that observed in the other groups (Fig. 3H). Interestingly, although the proliferation, migration, and tube formation capacity was higher in the group treated with $\mathrm{M} 13^{\mathrm{R}}$ than in untreated group and the group treated with $\mathrm{M} 13^{\mathrm{WT}}$, treatment with $\mathrm{M} 13^{\mathrm{R}+\mathrm{S}}$ showed a 


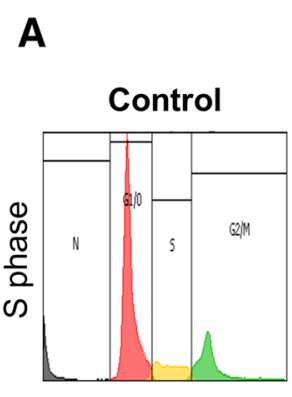

$12.9 \%$

C

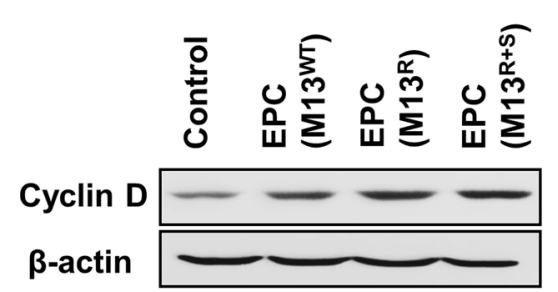

B

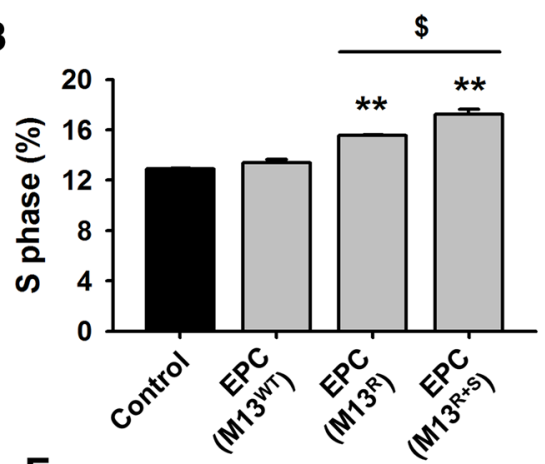

D

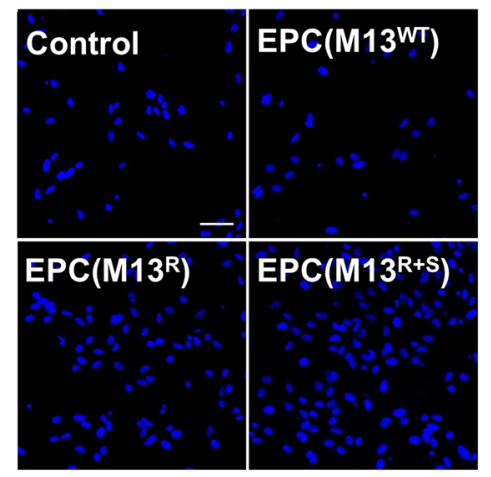

E

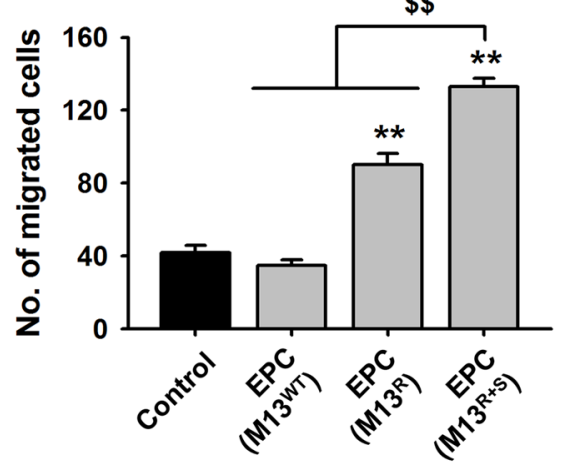

F

Control

$\operatorname{EPC}\left(M 13^{W T}\right)$

$\operatorname{EPC}\left(M 13^{R}\right)$

$\operatorname{EPC}\left(\mathrm{M} 13^{\mathrm{R}+\mathrm{S}}\right)$

$\mathbf{O h}$
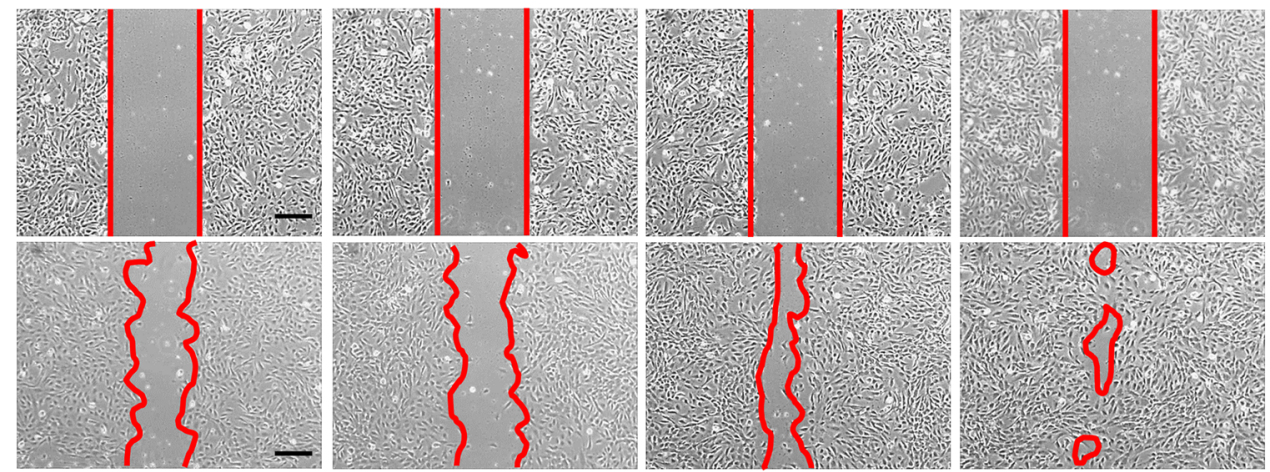

G

$\operatorname{EPC}\left(M 13^{W T}\right)$

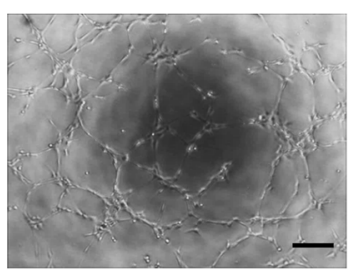

$\operatorname{EPC}\left(M 13^{R}\right)$

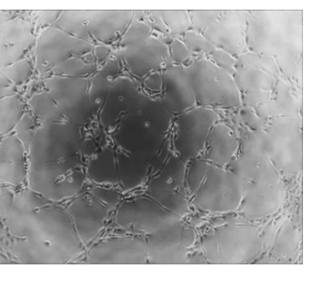

$\operatorname{EPC}\left(M 13^{R+S}\right)$
H

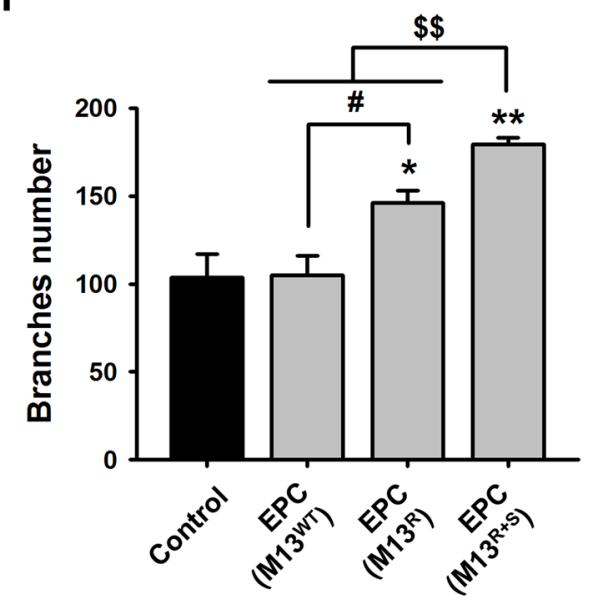


4Fig. 3 Assessment of the effect of the engineered M13 nanophage on the bioactivities of the EPCs. A The number of cells in different phases of the cell cycle-G0/G1, S, and G2/M-in the EPCs treated with the engineered M13 phage was determined by flow cytometry analysis of the PI-stained cells. B Quantification of the percentage of cells in the $\mathrm{S}$ phase. Values are expressed as the mean $\pm \mathrm{SEM}$. $* * p<0.01$ versus control and $\$ p<0.05$ versus EPCs treated with the M13 phage displaying RGD and SDKP peptide. C Cyclin D expression in the EPCs treated with the engineered M13 phage was assessed by western blot analysis. D Migration capacity of the EPCs treated with the engineered M13 phages was investigated using a trans-well migration assay. Migrated cells were stained with DAPI (blue). Scale bar $=50 \mu \mathrm{m}$. E Quantification of the migrated EPCs treated with the engineered M13 phage. Values are expressed as the mean \pm SEM. $* * p<0.01$ versus control and $\$ \$ p<0.01$ versus EPCs treated with M13 phage displaying RGD and SDKP peptide. F Migration of the EPCs treated with the engineered M13 phage was evaluated using the scratched wound healing assay. Scale bar $=100 \mu \mathrm{m}$. G Tube formation capacity of the EPCs treated with the engineered M13 phage was assessed using the Matrigel tube formation assay. Scale bar $=100 \mu \mathrm{m}$. H Quantification of tube branched number of the EPCs treated with the engineered M13 phage. Values are expressed as the mean \pm SEM. $* p<0.05$, $* * p<0.01$ versus control, $\# p<0.05$ vs. EPCs treated with M13 phage displaying RGD, and $\$ \$ p<0.01$ versus EPCs treated with M13 phage displaying RGD and SDKP peptide. (Color figure online)

maximal effect on the bioactivities of the EPCs. Our results indicate that the M13 phage displaying both RGD and SDKP enhanced the bioactivities such as proliferation, migration, and tube formation in the EPCs, thus suggesting that RGD and SDKP show a synergistic effect.

\subsection{M13 nanofiber displaying both RGD and SDKP enhances anti-oxidant and anti-inflammatory effects in EPCs}

To investigate the anti-oxidant effect of the engineered M13 nanofiber in EPCs, the expression of the anti-oxidant proteins peroxiredoxin I (PRX I) and PRX II was assessed using western blot. The levels of PRX I and PRX II were significantly increased in the group treated with $M 13^{R}$ and $\mathrm{M} 13^{\mathrm{R}+\mathrm{S}}$ compared to that in the untreated group or the group treated with M13 ${ }^{\mathrm{WT}}$ (Fig. 4A). In particular, PRX II expression was significantly increased in the group treated with $\mathrm{M} 13^{\mathrm{R}+\mathrm{S}}$ compared to that in the group treated with $\mathrm{M}_{13}^{\mathrm{R}}$ (Fig. 4A). These results show that treatment with $\mathrm{M} 13^{\mathrm{R}+\mathrm{S}}$ enhances the anti-oxidant effect in EPCs by increasing endogenous PRX I and PRX II levels.

To determine whether the engineered M13 nanofiber regulated the apoptosis-associated signal pathway in the EPCs, activation of apoptosis-associated mitogen-activated protein kinases (MAPKs) including c-Jun N-terminal kinase (JNK) and p38 was confirmed under long-term hypoxic conditions $(48 \mathrm{~h})$. Western blot revealed that treatment with $\mathrm{M} 13^{\mathrm{R}+\mathrm{S}}$ inhibited the phosphorylation of
JNK and p38 under long-term hypoxia (Fig. 4B). These results suggest that $S D K P$ inhibits the activation of p38 and JNK in response to hypoxia-induced oxidative stress. To confirm the anti-inflammatory effect of the engineered M13 nanofiber in EPCs, the expression of monocyte chemoattractant protein 1 (MCP-1), a pro-inflammatory cytokine, was assessed using western blot. Long-term hypoxia (48 h) increased the level of MCP-1 in the EPCs, but treatment with $\mathrm{M} 13^{\mathrm{R}+\mathrm{S}}$ significantly inhibited MCP-1 expression (Fig. 4C).

To explore the anti-oxidant and anti-inflammatory effect of the engineered M13 nanofiber in vivo, EPCs treated with the engineered M13 nanofiber were transplanted in ischemic tissues of a murine hindlimb ischemia model. After postoperative day 3, PRX I, PRX II, and MCP-1 expression in the ischemic tissues was assessed by immunofluorescent staining. The expression of the antioxidant enzymes PRX I and PRX II was significantly higher after transplantation of the EPCs treated with $\mathrm{M} 13^{\mathrm{R}+\mathrm{S}}$ compared to that observed for the other groups (Fig. 4D, E). MCP-1 levels were markedly decreased in the group transplanted with EPCs treated with $\mathrm{M} 13^{\mathrm{R}+\mathrm{S}}$ compared to that in the other groups (Fig. 4F). These findings suggest that the M13 nanofiber displaying both RGD and SDKP exerted an anti-oxidant and anti-inflammatory effect in EPCs by augmenting PRX I and PRX II levels and inhibiting MCP-1 expression.

\subsection{Transplantation of EPCs treated with the engineered M13 nanofiber improved functional recovery in a murine hindlimb ischemia model}

To determine whether the transplantation of EPCs treated with the engineered M13 nanofiber improves vascular regeneration, blood perfusion and tissue repair were examined following transplantation of the EPCs into the ischemic thigh of the murine hindlimb ischemia model. Groups of animals were transplanted with phosphate buffered saline (PBS), EPCs, and EPCs treated with M13 ${ }^{\mathrm{WT}}$, $\mathrm{M} 13^{\mathrm{R}}$, or $\mathrm{M} 13^{\mathrm{R}+\mathrm{S}}$, and blood perfusion was confirmed using laser Doppler perfusion imaging (LDPI) at postoperative days $0,3,7,14,21$, and 28 (Fig. 5A). The ratio of blood perfusion was significantly improved in the group transplanted with EPCs treated with $\mathrm{M} 13^{\mathrm{R}+\mathrm{S}}$ compared to that in the other groups (Fig. 5B). Transplantation of EPCs treated with $\mathrm{M} 13^{\mathrm{R}+\mathrm{S}}$ resulted in significantly reduced limb loss, foot necrosis, and toe loss compared to that in the other groups (Fig. 5C, D).

To determine the effect of the engineered M13 nanofiber on EPC-mediated neovessel formation, the densities of the arterioles and capillaries were quantified by immunofluorescent staining for $\alpha$-SMA and CD31 in the ischemic 
A
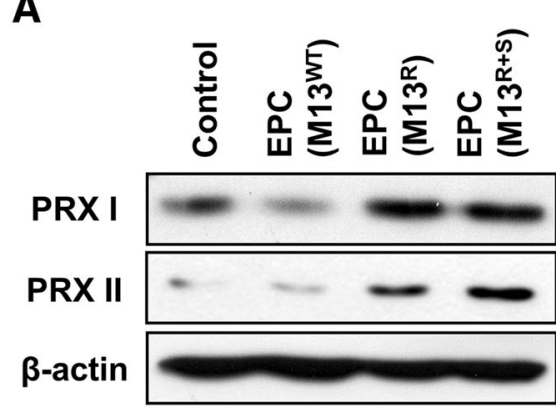

C

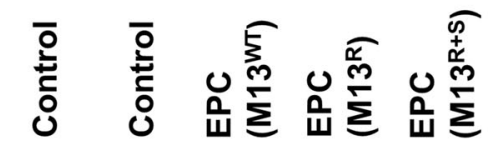

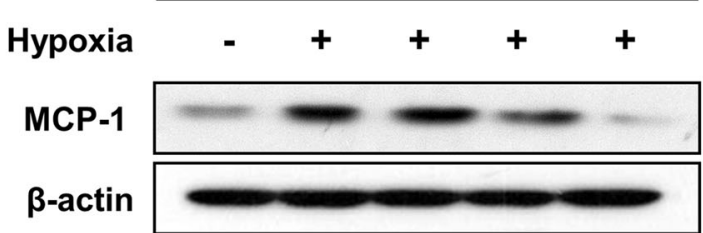

D

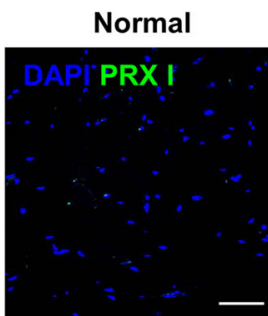

E

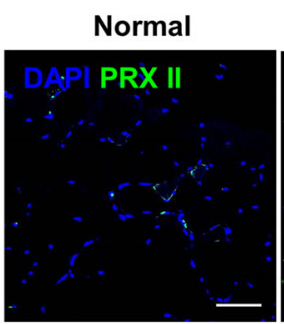

F
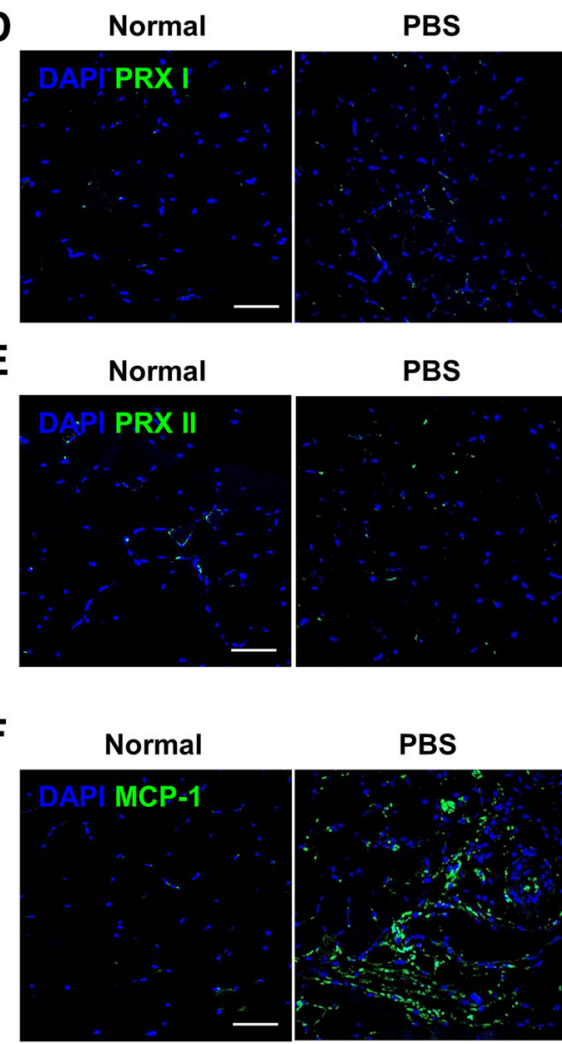

PBS

PBS
B

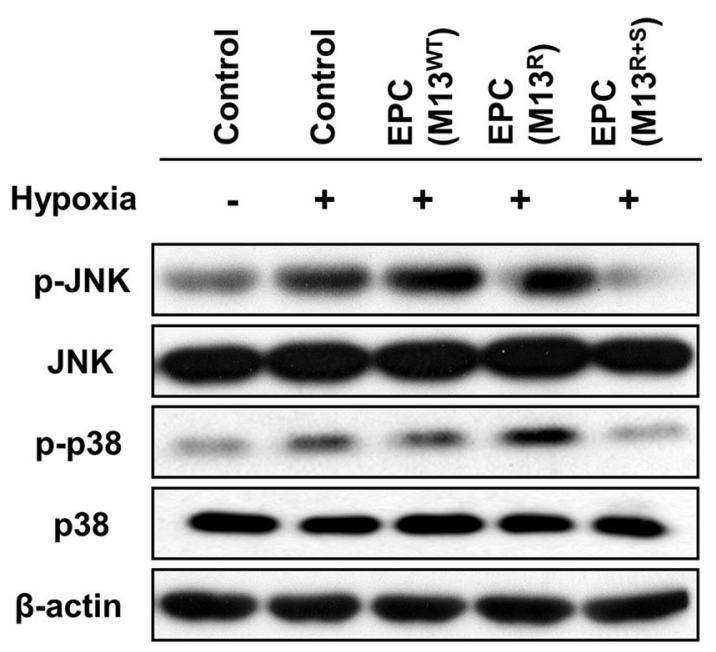

Control EPC

$\operatorname{EPC}\left(M 13^{W T}\right)$

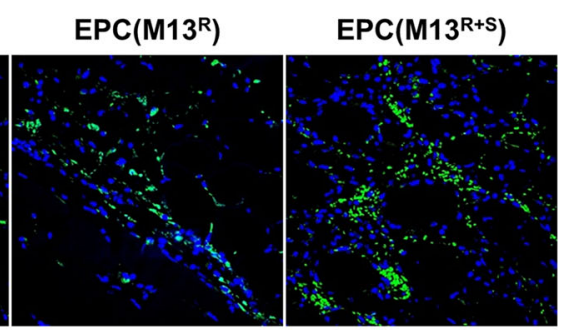

Control EPC

$\operatorname{EPC}\left(M 13^{W T}\right)$

$\operatorname{EPC}\left(M 13^{R}\right)$

$\operatorname{EPC}\left(M 13^{\mathrm{R}+\mathrm{S}}\right)$

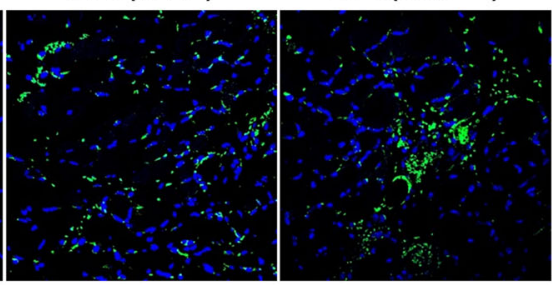

Control EPC

$\operatorname{EPC}\left(M 13^{W T}\right)$

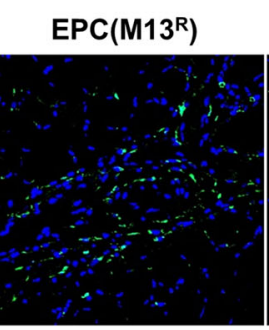

$\operatorname{EPC}\left(M 13^{R+S}\right)$
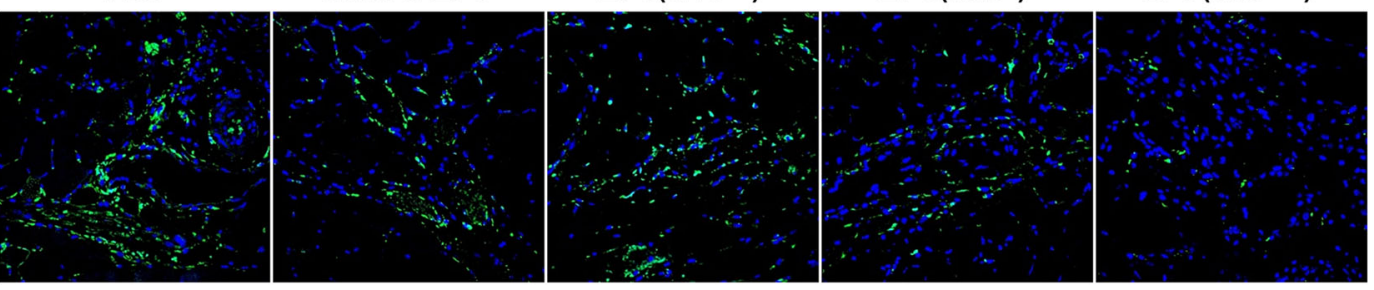
4Fig. 4 Anti-oxidant and anti-inflammatory effect of the engineered M13 phage on the EPCs. A After treatment with the engineered M13 phage for $24 \mathrm{~h}$, the expression of the anti-oxidant enzymes peroxiredoxin I (PRX I) and PRX II in the EPCs was confirmed by western blot analysis. B After the EPCs were incubated in hypoxic conditions for $48 \mathrm{~h}$, the activation of the apoptosis-mediated MAPKs JNK and p38 was assessed by western blot analysis. C After the EPCs were incubated in hypoxic conditions for $48 \mathrm{~h}$, the levels of MCP-1 were assessed by western blot analysis. D-F EPCs treated with the engineered M13 phage were transplanted into the ischemic region of a murine hindlimb ischemia model. At postoperative day 3 , the ischemic thigh tissues were subjected to immunofluorescent staining to detect PRX I, PRX II, and MCP-1 (green). The nuclei were stained with DAPI (blue). Scale bar $=50 \mu \mathrm{m}$. (Color figure online)

tissues at postoperative day 28 (Fig. 5E, F). Immunofluorescent staining indicated that the number of $\alpha$-SMA-positive arterioles and CD31-positive capillaries was significantly increased in the ischemic sites of mice injected with EPCs treated with $\mathrm{M} 13^{\mathrm{R}+\mathrm{S}}$ than in the other groups (Fig. 5G, H).

To investigate the proliferation and survival of the transplanted EPCs, immunofluorescent staining was performed on the ischemic tissues at postoperative day 3. The proliferation of the transplanted EPCs was assessed by counting the number of proliferating cell nuclear antigen (PCNA) and human nuclear antigen (HNA) double-positive cells (Fig. 6A), and the apoptosis of the transplanted EPCs was evaluated by counting the number of cleaved caspase-3 and HNA double-positive cells (Fig. 6B). The proliferation of the transplanted EPCs was significantly higher in the $\mathrm{M} 13^{\mathrm{R}+\mathrm{S}}$-treated groups than in the other groups (Fig. 6C), and the apoptosis of the transplanted EPCs was significantly lower in the M13 ${ }^{\mathrm{R}+\mathrm{S}}$-treated EPCs compared to that in the other groups (Fig. 6D).

To verify the differentiation of the transplanted EPCs into endothelial cells, immunofluorescent staining for human-specific CD31 and mouse-specific CD31 was performed at postoperative day 28 (Fig. 6E). Immunofluorescent staining revealed that the endothelial differentiation of the transplanted EPCs was significantly higher in the mice injected with $\mathrm{M} 13^{\mathrm{R}+\mathrm{S}}$-treated EPCs than in the other groups (Fig. 6F). These findings suggest that SDKP is a key molecule for enhancing neovascularization.

\section{Discussion}

Stem and progenitor cell transplantation shows great promise as a novel strategy for ischemic regenerative therapy. However, low efficacy of engraftment and survival of transplanted cells within ischemic injured area is a major limitation for pre- and clinical application. To address this issue, this study showed that engineered RGD and SDKP- displaying M13 nanofiber enhanced the functionalities of EPCs by regulating intracellular and extracellular process.

In the present study, we developed the multifunctional RGD and SDKP-displaying M13 nanofiber as delivery molecule (RGD), artificial niche component (RGD) and cell stimulator (SDKP). Previous studies have reported that cell adhesion is enhanced on a matrix expressing RGD [17, 29]. RGD-coated sterically stabilized doxorubicinloaded liposomes enhance intracellular drug delivery by integrin-mediated endocytosis [30]. Moreover, RGD-displaying M13 phages exhibited higher internalization efficiency than the wild type M13 phage in HeLa cells expressing integrins on their cell membrane [14]. SDKP as a key effective peptide of thy thymosin $\beta 4$ enhances proliferation, anti-oxidant effect, anti-apoptotic activity, and immunomodulation [23].

We revealed that RGD and SDKP-displaying M13 nanofiber promoted EPC proliferation through regulation of cyclin D expression. A previous report showed that an M13 phage displaying RGD enhances the proliferative potential of neural progenitor cells and human fibroblasts [27, 31], and the interaction between integrin, which is the RGD-binding receptor, and its ligand lead to cell proliferation through focal adhesion kinase-cyclin D pathway [32]. Ac-SDKP augments cell proliferation in endothelial cells and smooth muscle cells [24, 33]. In addition, engineered M13 nanofiber increased migration and tube formation capacity in EPCs. In a previous study, an RGDmimetic small molecule was found to promote endothelial cell migration by promoting VEGFR2 expression [34]. Moreover, AC-SDKP has also been shown to increase the migration capacity and the ability to form tube-like structures in endothelial cells [24]. Furthermore, engineered M13 phage activated anti-oxidant effect by regulating PRX and MAPK, and enhanced anti-inflammatory activity through inhibition of MCP-1 expression against oxidative stress. The anti-oxidant activity of PRX is critical for protecting cellular components from oxidative stress [35, 36]. PRX knockdown induces cell apoptosis by increasing oxidative stress, while PRX overexpression prevents cell death [37]. Hypoxia-induced ROS activates JNK and p38, resulting in inflammatory reactions and apoptosis [38]. Fifteen thymosin $\beta 4$-derived peptides containing SDKP promote cell survival and prevent apoptosis [23]. In addition, Ac-SDKP is known to inhibit macrophage infiltration into the left ventricle in a rat myocardial infarction model [39]. Ac-SDKP was also shown to attenuate renal inflammation in a unilateral ureteral obstruction model by inhibiting MCP-1 expression [40]. Taken together, our findings indicate that engineered M13 nanofiber accelerates the functionalities of EPC via RGD as extracellular regulator and SDKP as intracellular regulator. 

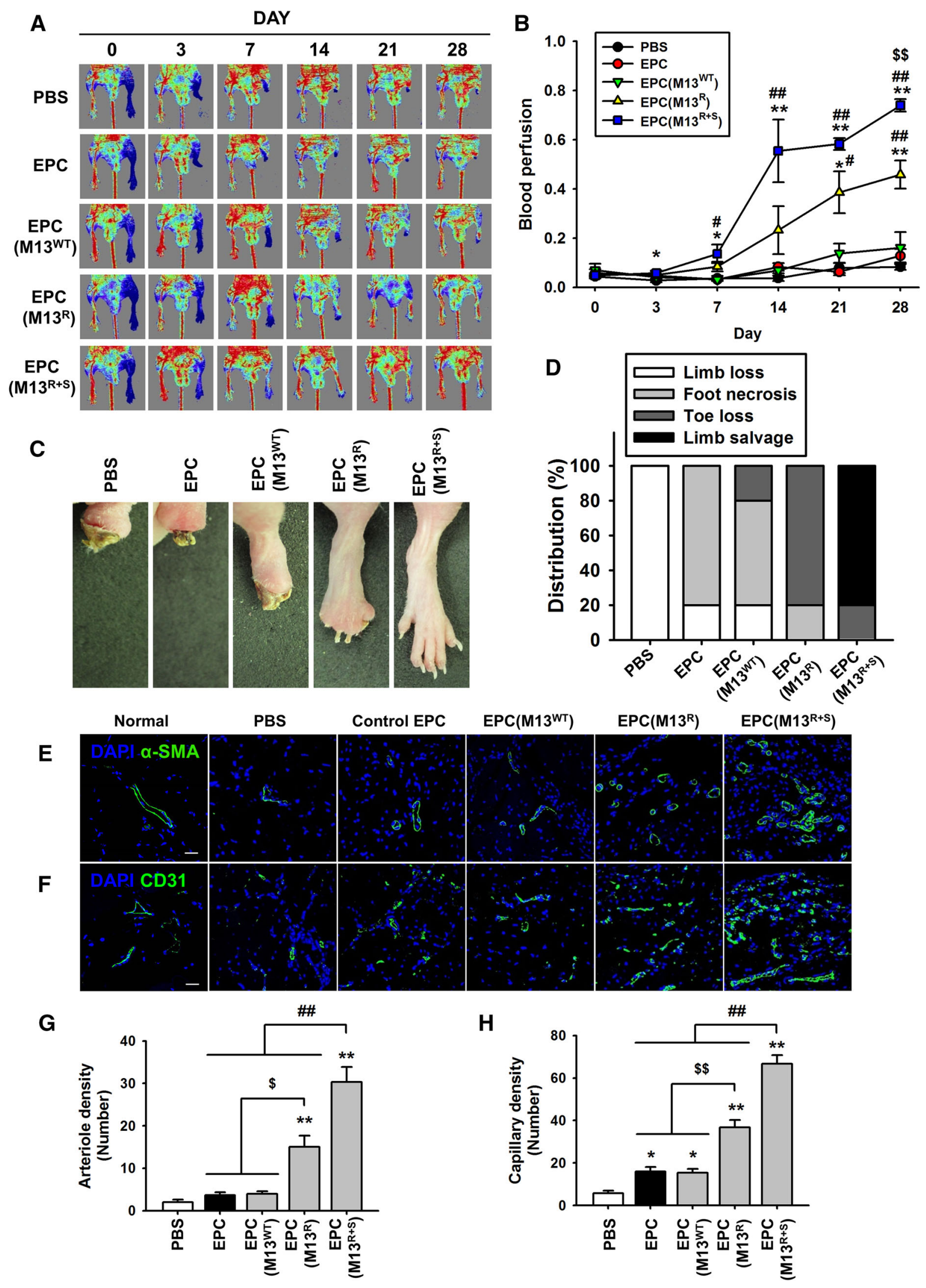
4Fig. 5 Assessment of the functional recovery in the murine hindlimb ischemia model. A The murine hindlimb ischemia model was established using Balb/C nude mice. The ratio of blood perfusion was assessed by laser Doppler perfusion imaging analysis in the ischemic limbs of the mice injected with PBS, untreated EPCs (EPC), EPCs treated with the wild type M13 phage (EPC (M13 $\left.{ }^{\mathrm{WT}}\right)$ ), EPCs treated with M13 phage displaying RGD only (EPC (M13 $\left.{ }^{\mathrm{R}}\right)$ ), and EPCs treated with M13 phage displaying both RGD and SDKP (EPC $\left.\left(\mathrm{M} 13^{\mathrm{R}+\mathrm{S}}\right)\right)$ at $0,3,7,14,21$, and 28 days post-surgery. $\mathrm{B}$ The ratio of blood perfusion was measured, and values are expressed as the mean \pm SEM. $* p<0.05, \quad * * p<0.01$ versus PBS, $\# p<0.05$, $\# \# p<0.01$ versus EPC $\left(\mathrm{M} 13^{\mathrm{WT}}\right)$, and $\$ \$ p<0.01$ versus EPC $\left(\mathrm{M} 13^{\mathrm{R}+\mathrm{S}}\right)$. C Representative images illustrating the various outcomes (limb loss, foot necrosis, toe lose, and limb salvage) of the ischemic limbs at post-operative day 28. D Distribution of the different outcomes at postoperative day 28 . E, F At 28 days post-operation, the ischemic limb tissues were analyzed for vessel regeneration at the injured sites. Vessel formation was investigated by immunofluorescent staining for $\alpha$-SMA(E) (arteriole density, green) and CD31(F) (capillary density, green). Scale bar $=20 \mu \mathrm{m}$. G, H Standard quantification of arteriole density $(\mathbf{G})$ and capillary density $(\mathbf{H})$ represented as the number of $\alpha$-SMA- and CD31-positive cells per highpower field. Values are expressed as the mean \pm SEM. $* p<0.05$, $*^{*} p<0.01$ versus PBS, $\$ p<0.05, \$ \$ p<0.01$ versus EPC $\left(\mathrm{M} 13^{\mathrm{R}}\right)$, and $\# \# p<0.01$ versus EPC $\left(\mathrm{M} 13^{\mathrm{R}+\mathrm{S}}\right)$. (Color figure online)

Transplantation of stem and progenitor cells is a promising therapeutic strategy for ischemic diseases, but ischemia injury-induced pathophysiological conditions such as oxidative stress and inflammation lead to low therapeutic efficacy $[4,41]$. Transplantation of functional EPCs by stimulation of growth factors or transduction of functional genes is known to enhance neovascularization by increasing the survival, proliferation, incorporation, and endothelial differentiation of transplanted cells [2, 42-44]. To promote survival and function of EPC in ischemic injured tissues, EPCs treated with M13 nanofiber were transplanted in a murine hindlimb ischemia model, resulting that M13 nanofiber enhanced EPC survival, neovascularization, and functional recovery in a murine hindlimb ischemia model. Thymosin $\beta 4$ and Ac-SDKP promote angiogenesis in vitro and in vivo [24, 45]. In addition, in a murine acute myocardial infarction model, Ac-SDKP has been shown to improve heart function by inhibiting macrophage activation [46]. Although the functional recovery was significantly lower in the group transplanted with the EPCs treated with $M 13^{\mathrm{R}}$ than in the group transplanted with EPCs treated with $\mathrm{M} 13^{\mathrm{R}+\mathrm{S}}$, the transplantation of EPCs treated with $\mathrm{M} 13^{\mathrm{R}}$ resulted in significantly better functional recovery compared to that observed with the injection of PBS, non-treated EPCs, and EPCs treated with $\mathrm{M} 13^{\mathrm{WT}}$. It has been found that low concentrations of RGDbased contrast agents promote VEGFR2 recycling in endothelial cells and VEGF-mediated angiogenesis [34]. Moreover, RGD-modified alginate increases angiogenesis in myocardial infarction by regulating the ischemic microenvironment [47]. These findings suggest that adopted RGD, in part, affects the ECM niche by RGD-integrin docking. Taken together, our results clearly showed that the transplantation of EPCs treated with the engineered M13 nanofiber displaying both RGD and SDKP synergistically improved neovascularization and limb salvage in the murine hindlimb ischemia model by activating the intracellular and extracellular processes of the primed EPCs, including cell survival, proliferation, and endothelial differentiation of the transplanted cells.

To the best of our knowledge, this is the first study to show that engineered M13 nanofibers can deliver effective functional peptides into targeted cells by docking RGD peptides with high affinities for integrin-expressing cell surfaces and simultaneously releasing $\sim 2700$ SDKP peptides per M13 phage for priming the intracellular signals of EPCs. Our engineered M13 nanofiber displaying both RGD and SDKP promoted the bioactivities of EPCs, including proliferation, migration, and tube formation. In addition, the transplanted EPCs treated with the engineered M13 bacteriophage significantly improved neovascularization, thus representing significant therapeutic efficacy in a murine hindlimb ischemia model. In particular, RGD could not only bind and dock to integrin-expressing cell surfaces, but also facilitate cell-ECM niche formation, suggesting that the harbored RGD and SDKP motifs on the M13 nanofiber represent dual and synergetic effects for enhancing the functions of the EPCs.

Our findings provide one of applicants for novel bio-safe and biocompatible therapeutics, as well as a breakthrough for cell therapy strategies. However, although non-therapeutic applications of bacteriophages approved from Food and Drug Administration, United States Department of Agriculture, and United States Environmental Protection Agency, additional efforts are needed to ensure safety for clinical application [48]. The major advantages of our engineered M13 nanofiber-based peptide delivery and priming system for stem/progenitor cells to target specific cell receptors are as follows: (1) It is cheaper than direct treatment with cytokines and drugs. (2) The system can be produced more easily than a nanoparticle or a physical delivery system because of the characteristics of the M13 bacteriophage, such as self-replication, self-evolution, and self-assembly [10, 49]. (3) Our system represents a more bio-safe method than genetic modification methods. (4) It can be simply expanded for other applications and can be expected to provide multiple combinational and synergistic effects; i.e., other cell surface-binding peptides and functionally effective signaling molecules related to stem cell survival and/or engraftment in the ischemic tissue can be harbored on the M13 nanofiber. In conclusion, we, for the first time, showed that our engineered M13 nanofiber displaying both RGD and SDKP is an effective therapeutic 


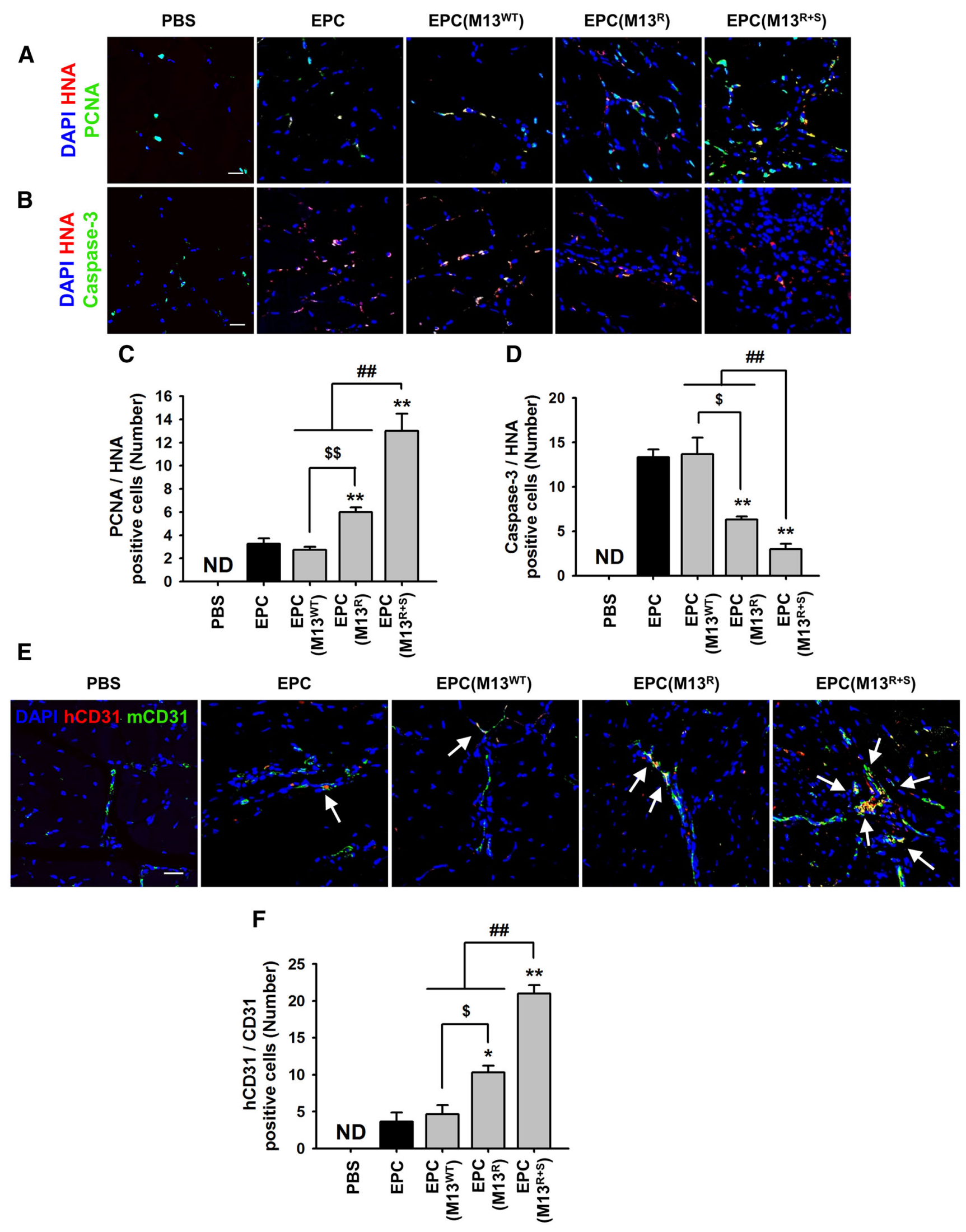


4Fig. 6 Effect of the engineered M13 nanophage on the proliferation, incorporation, and endothelial differentiation of the transplanted EPCs at the ischemic sites. At 3 days post-operation, the ischemic limb tissues were analyzed to determine the proliferation and survival of the transplanted EPCs treated with the engineered M13 phage at injured sites. A The proliferation of the transplanted cells in the ischemic injured tissues was visualized by immunofluorescent staining for human nuclear antibody (HNA, red) and proliferating cell nuclear antigen (PCNA, green). Scale bar $=20 \mu \mathrm{m}$. B The apoptosis of the transplanted cells in the ischemic injured tissues was visualized by immunofluorescent staining for human nuclear antibody (HNA, red) and cleaved caspase-3 (caspase-3, green). Scale bar $=20 \mu \mathrm{m}$. C The number of proliferating transplanted cells was quantified by counting the number of PCNA and HNA doublepositive cells per high-power field. Values are expressed as the mean \pm SEM. $* * p<0.01$ versus EPC, $\$ \$ p<0.01$ versus EPC $\left(\mathrm{M} 13^{\mathrm{R}}\right)$, and \#\#p $<0.01$ versus EPC $\left(\mathrm{M} 13^{\mathrm{R}+\mathrm{S}}\right)$. D The apoptosis in the transplanted cells was quantified by counting the number of cleaved caspase-3 and HNA double-positive cells per high-power field. Values are expressed as the mean \pm SEM. $* * p<0.01$ versus

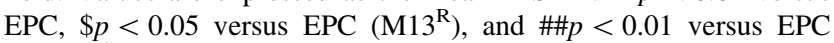
$\left(\mathrm{M} 13^{\mathrm{R}+\mathrm{S}}\right)$. E At 28 days post-operation, the ischemic tissues were analyzed to determine the endothelial differentiation of the transplanted EPCs treated with the engineered M13 phage at the injured sites. Endothelial differentiation of the transplanted EPCs was visualized by immunofluorescent staining for human-specific CD31 antibody (hCD31, red) and mouse-specific CD31 antibody (mCD31, green). The arrows indicate endothelial differentiation of the transplanted EPCs at the injured tissues. Scale bar $=20 \mu \mathrm{m}$. F The number of endothelial differentiated cells was quantified by counting the number of hCD31 and mCD31 double-positive cells per highpower field. Values are expressed as the mean \pm SEM. $* p<0.05$, $*^{*} p<0.01$ versus EPC, $\$ p<0.01$ versus EPC $\left(\mathrm{M} 13^{\mathrm{R}}\right)$, and $\# \# p 0.01$ versus EPC $\left(\mathrm{M} 13^{\mathrm{R}+\mathrm{S}}\right)$. (Color figure online)

strategy for EPC-based neovascularization in ischemic diseases, thus providing critical evidence indicating that the novel M13 nanofiber engineering system could be a useful tool for targeted cell-specific peptide delivery.

Acknowledgements This work was supported by a grant from the National Research Foundation (NRF-2015M3A9B4051053, NRF2015R1A5A2009656, NRF-2014R1A1A2056907), Korean Health Technology R\&D Project, Ministry of Health and Welfare (HI13C1256, HI14C1863) funded by the Korean government, and the [2015 Post-Doc. Development Program] of Pusan National University.

\section{Compliance with ethical standards}

Conflict of interest The authors have no financial conflicts of interest.

Ethical statement This study including all surgical interventions and postoperative animal care was approved by the Institutional Review Board of the Pusan National University Yangsan Hospital, Republic of Korea (Approval No. PNUH-2012-19).

\section{References}

1. Asahara T, Murohara T, Sullivan A, Silver M, van der Zee R, Li $\mathrm{T}$, et al. Isolation of putative progenitor endothelial cells for angiogenesis. Science. 1997;275:964-7.
2. Asahara T, Kawamoto A, Masuda H. Concise review: circulating endothelial progenitor cells for vascular medicine. Stem Cells. 2011;29:1650-5.

3. Fadini GP, Losordo D, Dimmeler S. Critical reevaluation of endothelial progenitor cell phenotypes for therapeutic and diagnostic use. Circ Res. 2012;110:624-37.

4. Wu KH, Mo XM, Han ZC, Zhou B. Stem cell engraftment and survival in the ischemic heart. Ann Thorac Surg. 2011;92:191725.

5. Liu L, Rando TA. Manifestations and mechanisms of stem cell aging. J Cell Biol. 2011;193:257-66.

6. Hofmeister CC, Zhang J, Knight KL, Le P, Stiff PJ. Ex vivo expansion of umbilical cord blood stem cells for transplantation: growing knowledge from the hematopoietic niche. Bone Marrow Transplant. 2007;39:11-23.

7. Tongers J, Losordo DW, Landmesser U. Stem and progenitor cell-based therapy in ischaemic heart disease: promise, uncertainties, and challenges. Eur Heart J. 2011;32:1197-206.

8. Smith GP, Petrenko VA. Phage display. Chem Rev. 1997;97: 391-410.

9. Lee SW, Belcher AM. Virus-based fabrication of micro- and nanofibers using electrospinning. Nano Lett. 2004;4:387-90.

10. Chung WJ, Oh JW, Kwak K, Lee BY, Meyer J, Wang E, et al. Biomimetic self-templating supramolecular structures. Nature. 2011;478:364-8.

11. Wang JL, Wang L, Li X, Mao CB. Virus activated artificial ECM induces the osteoblastic differentiation of mesenchymal stem cells without osteogenic supplements. Sci Rep. 2013;3:1242.

12. Wang YA, Yu X, Overman S, Tsuboi M, Thomas GJ, Egelman $\mathrm{EH}$. The structure of a filamentous bacteriophage. J Mol Biol. 2006;361:209-15.

13. Hart SL, Knight AM, Harbottle RP, Mistry A, Hunger HD, Cutler DF, et al. Cell-binding and internalization by filamentous phage displaying a cyclic Arg-Gly-Asp-containing peptide. J Biol Chem. 1994;269:12468-74.

14. Choi DS, Jin HE, Yoo SY, Lee SW. Cyclic RGD peptide incorporation on phage major coat proteins for improved internalization by HeLa cells. Bioconjug Chem. 2014;25:216-23.

15. Shin YC, Lee JH, Jin OS, Lee EJ, Jin LH, Kim CS, et al. RGD peptide-displaying M13 bacteriophage/PLGA nanofibers as celladhesive matrices for smooth muscle cells. J Korean Phys Soc. 2015;66:12-6.

16. Shin YC, Lee JH, Jin L, Kim MJ, Kim C, Hong SW, et al. Celladhesive matrices composed of RGD peptide-displaying M13 bacteriophage/poly(lactic-co-glycolic acid) nanofibers beneficial to myoblast differentiation. J Nanosci Nanotechnol. 2015; 15:7907-12.

17. Shin YC, Lee JH, Jin L, Kim MJ, Oh JW, Kim TW, et al. Celladhesive RGD peptide-displaying M13 bacteriophage/PLGA nanofiber matrices for growth of fibroblasts. Biomater Res. 2014;18:14.

18. Shin YC, Lee JH, Kim MJ, Hong SW, Kim B, Hyun JK, et al. Stimulating effect of graphene oxide on myogenesis of $\mathrm{C} 2 \mathrm{C} 12$ myoblasts on RGD peptide-decorated PLGA nanofiber matrices. J Biol Eng. 2015;9:22.

19. Chiarugi P, Giannoni E. Anoikis: a necessary death program for anchorage-dependent cells. Biochem Pharmacol. 2008;76: 1352-64.

20. Even-Ram S, Artym V, Yamada KM. Matrix control of stem cell fate. Cell. 2006;126:645-7.

21. Keselowsky BG, Collard DM, Garcia AJ. Integrin binding specificity regulates biomaterial surface chemistry effects on cell differentiation. Proc Natl Acad Sci U S A. 2005;102:5953-7.

22. Wang J, Wang L, Li X, Mao C. Virus activated artificial ECM induces the osteoblastic differentiation of mesenchymal stem cells without osteogenic supplements. Sci Rep. 2013;3:1242. 
23. Sosne G, Qiu P, Goldstein AL, Wheater M. Biological activities of thymosin beta4 defined by active sites in short peptide sequences. FASEB J. 2010;24:2144-51.

24. Wang D, Carretero OA, Yang XY, Rhaleb NE, Liu YH, Liao TD, et al. N-acetyl-seryl-aspartyl-lysyl-proline stimulates angiogenesis in vitro and in vivo. Am J Physiol Heart Circ Physiol. 2004;287:H2099-105.

25. Lee SH, Lee JH, Yoo SY, Hur J, Kim HS, Kwon SM. Hypoxia inhibits cellular senescence to restore the therapeutic potential of old human endothelial progenitor cells via the hypoxia-inducible factor- $1 \alpha$-TWIST-p21 axis. Arterioscler Thromb Vasc Biol. 2013;33:2407-14.

26. Qi D, Scholthof KB. A one-step PCR-based method for rapid and efficient site-directed fragment deletion, insertion, and substitution mutagenesis. J Virol Methods. 2008;149:85-90.

27. Merzlyak A, Indrakanti S, Lee SW. Genetically engineered nanofiber-like viruses for tissue regenerating materials. Nano Lett. 2009;9:846-52.

28. Bhattarai SR, Yoo SY, Lee SW, Dean D. Engineered phagebased therapeutic materials inhibit Chlamydia trachomatis intracellular infection. Biomaterials. 2012;33:5166-74.

29. Zhang L, Hum M, Wang M, Li Y, Chen H, Chu C, et al. Evaluation of modifying collagen matrix with RGD peptide through periodate oxidation. J Biomed Mater Res A. 2005;73:468-75.

30. Xiong XB, Huang Y, Lu WL, Zhang X, Zhang H, Nagai T, et al. Intracellular delivery of doxorubicin with RGD-modified sterically stabilized liposomes for an improved antitumor efficacy: in vitro and in vivo. J Pharm Sci. 2005;94:1782-93.

31. Yoo SY, Chung WJ, Kim TH, Le M, Lee SW. Facile patterning of genetically engineered M13 bacteriophage for directional growth of human fibroblast cells. Soft Matter. 2011;7:363-8.

32. Liu J, Liu S, Chen Y, Zhao X, Lu Y, Cheng J. Functionalized self-assembling peptide improves INS-1 $\beta$-cell function and proliferation via the integrin/FAK/ERK/cyclin pathway. Int $\mathbf{J}$ Nanomedicine. 2015;10:3519-31.

33. Liu JM, Lawrence F, Kovacevic M, Bignon J, Papadimitriou E, Lallemand JY, et al. The tetrapeptide AcSDKP, an inhibitor of primitive hematopoietic cell proliferation, induces angiogenesis in vitro and in vivo. Blood. 2003;101:3014-20.

34. Reynolds AR, Hart IR, Watson AR, Welti JC, Silva RG, Robinson SD, et al. Stimulation of tumor growth and angiogenesis by low concentrations of RGD-mimetic integrin inhibitors. Nat Med. 2009;15:392-400.

35. Fisher AB. Peroxiredoxin 6: a bifunctional enzyme with glutathione peroxidase and phospholipase $\mathrm{A}_{2}$ activities. Antioxid Redox Signal. 2011;15:831-44.
36. Knoops B, Goemaere J, Van der Eecken V, Declercq JP. Peroxiredoxin 5: structure, mechanism, and function of the mammalian atypical 2-Cys peroxiredoxin. Antioxid Redox Signal. 2011;15:817-29.

37. Hampton MB, O'Connor KM. Peroxiredoxins and the regulation of cell death. Mol Cells. 2016;39:72-6.

38. Matsuzawa A, Ichijo H. Redox control of cell fate by MAP kinase: physiological roles of ASK1-MAP kinase pathway in stress signaling. Biochim Biophys Acta. 2008;1780:1325-36.

39. Yang F, Yang XP, Liu YH, Xu J, Cingolani O, Rhaleb NE, et al. AcSDKP reverses inflammation and fibrosis in rats with heart failure after myocardial infarction. Hypertension. 2004;43:229-36.

40. Wang M, Liu R, Jia X, Mu S, Xie R. N-acetyl-seryl-aspartyllysyl-proline attenuates renal inflammation and tubulointerstitial fibrosis in rats. Int J Mol Med. 2010;26:795-801.

41. Monsel A, Zhu YG, Gennai S, Hao Q, Liu J, Lee JW. Cell-based therapy for acute organ injury: preclinical evidence and ongoing clinical trials using mesenchymal stem cells. Anesthesiology. 2014;121:1099-121.

42. Lee JH, Lee SH, Yoo SY, Asahara T, Kwon SM. CD34 hybrid cells promote endothelial colony-forming cell bioactivity and therapeutic potential for ischemic diseases. Arterioscler Thromb Vasc Biol. 2013;33:1622-34.

43. Cho JG, Lee JH, Hong SH, Lee HN, Kim CM, Kim SY, et al. Tauroursodeoxycholic acid, a bile acid, promotes blood vessel repair by recruiting vasculogenic progenitor cells. Stem Cells. 2015;33:792-805.

44. Lee JH, Lee SH, Choi SH, Asahara T, Kwon SM. The sulfated polysaccharide fucoidan rescues senescence of endothelial colonyforming cells for ischemic repair. Stem Cells. 2015;33:1939-51.

45. Cavasin MA. Therapeutic potential of thymosin-beta4 and its derivative $\mathrm{N}$-acetyl-seryl-aspartyl-lysyl-proline (Ac-SDKP) in cardiac healing after infarction. Am J Cardiovasc Drugs Drugs. 2006;6:305-11.

46. Ma X, Yuan Y, Zhang Z, Zhang Y, Li M. An analog of Ac-SDKP improves heart functions after myocardial infarction by suppressing alternative activation (M2) of macrophages. Int J Cardiol. 2014;175:376-8.

47. Yu J, Gu Y, Du KT, Mihardja S, Sievers RE, Lee RJ. The effect of injected RGD modified alginate on angiogenesis and left ventricular function in a chronic rat infarct model. Biomaterials. 2009;30:751-6.

48. Lu TK, Koeris MS. The next generation of bacteriophage therapy. Curr Opin Microbiol. 2011;14:524-31.

49. Oh JW, Chung WJ, Heo K, Jin HE, Lee BY, Wang E, et al. Biomimetic virus-based colourimetric sensors. Nat Commun. 2014;5:3043. 